Navigation Physics 3(1)(2021)
Navigation Physics
Journal of Physics Education

\title{
KOKAMI: The Innovation of Learning Impuls and Momentum in Senior High School
}

\author{
Siti Nur Fadillah ${ }^{1^{*}}$, Tatan Zenal Mutakin ${ }^{2}$ \\ ${ }^{1}$ SMA Negeri 16 Tangerang \\ ${ }^{2}$ Universitas Indraprasta PGRI \\ *E-mail: sitinurfadilah25@gmail.com
}

\begin{tabular}{|c|c|}
\hline Info Artikel & Abstract \\
\hline $\begin{array}{l}\text { Sejarah Artikel: } \\
\text { Diterima Maret } 2021 \\
\text { Disetujui Juni } 2021 \\
\text { Dipublikasikan Juni } 2021 \\
\\
\text { Keywords: } \\
\text { KOKAMI, learning media, critical } \\
\text { thinking skills, student activities }\end{array}$ & $\begin{array}{l}\text { Learning using learning media is very helpful for students in understanding } \\
\text { the subject matter. However, many learning media are not yet able to } \\
\text { involve students actively involved in learning. The purpose of this research } \\
\text { is to develop and implement KOKAMI learning media in the learning } \\
\text { process. The results showed that the media developed is very feasible and } \\
\text { able to improve students' learning outcomes, critical thinking skills and } \\
\text { improve students' learning activities. This learning medium is very suitable } \\
\text { to be applied in the implementation of the current curriculum. }\end{array}$ \\
\hline
\end{tabular}

How to Cite: Fadillah, S. N., \& Mutakin, T. Z. (2021). KOKAMI: The Innovation of Learning Impuls and Momentum in Senior High School. Navigation Physics: Journal of Physics Education, 3 (1), 16-21.

\section{PENDAHULUAN}

Pembelajaran fisika yang kreatif dan inovatif seharusnya dilakukan oleh guru dalam upaya menghasilkan siswa yang kreatif. Kualitas pembelajaran dilihat dari aktivitas siswa ketika belajar dan kreativitas yang dapat dilakukan oleh siswa setelah mengikuti pembelajaran. Pelajaran fisika mengandung prinsip, teori, dan hukum di dalamnya. Namun, pembelajaran fisika tidak hanya mempelajari itu semua tanpa ada tindak lanjut. Fisika tidak lepas dari berpikir kreatif, hal tersebut terbukti dari segala hukum, prinsip, dan teori yang ada saat ini adalah hasil pemikiran kreatif para ilmuwan terdahulu. Fisika mengandung banyak nilai karakter didalamnya, salah satu karakter yang dapat dikembangkan adalah berpikir kreatif. Fisika juga erat kaitannya dengan dengan kehidupan sehari-hari. Oleh karena itu, fisika merupakan ilmu pengetahuan yang perlu dan penting untuk dipelajari guna mengembangkan ilmu pengetahuan dan teknologi yang ada.

Berdasarkan data hasil observasi dan wawancara, fisika sering dianggap sebagai salah satu mata pelajaran yang rumit. Hal ini terlihat dari banyaknya siswa yang mengeluhkan kesulitan belajar fisika. Tidak sedikit siswa yang merasa jenuh dan bosan berada dalam kelas saat pelajaran fisika.Hal ini terlihat dari seringnya siswa yang meminta izin untuk ke kamar kecil saat kegiatan belajar berlangsung. Saat mengerjakan soal-soal yang diberikan guru,siswa merasa kesulitan. Penggunaan gadget yang sedang marak dikalangan remaja-pun turut mempengaruhi kondisi kelas. Saat guru menjelaskan materi, tidak semua siswa fokus memperhatikan guru. Beberapa siswa asik dengan gadget dan ada pula yang asik berbincang-bincang dengan teman sebangku. Dalam pembelajaran fisika metode yang dapat digunakan tidak hanya metode ceramah. Saat guru menjelaskan materi fisika dengan metode ceramah, siswa dapat dengan mudahnya mengerjakan hal lain dengan tidak memperhatikan guru. Siswa merasa jenuh jika hanya mendengarkan guru menjelaskan materi. Oleh karena itu, guru harus kreatif dalam menentukan cara mengajar yang digunakan dikelas. Agar siswa lebih tertarik pada pelajaran dan tidak merasa jenuh saat belajar fisika. Apalagi saat belajar fisika setelah jam istirahat ataupun di jam terakhir. Guru harus mampu membuat siswa fokus dan kondusif saat belajar.

Untuk menciptakan suasana belajar yang menyenangkan dan menarik minat siswa, guru dapat menggunakan metode belajar sambil bermain (Rosarian \& Dirgantoro, 2020). Salah satu media yang 
dapat digunakan dalam proses pembelajaran adalah pendekatan melalui media Kotak dan Kartu Misterius (KOKAMI). Media KOKAMI adalah gabungan antara media dan permainan yang mampu menarik minat siswa untuk ikut aktif terlibat dalam proses pembelajaran (Mauliana \& Rahmayiani, 2017). Permainan ini dapat merangsang daya pikir siswa sehingga mereka mampu memahami pesan atau materi yang diberikan (Paisah, Fatmaryanti \& Akhdinirwanto, 2013; Istiqomah, Widiyatmoko \& Wusqo, 2016; Putri, Prihandono, \& Putra, 2017). KOKAMI (Kotak dan kartu misterius) merupakan salah satu jenis media yang dikombinasikan dengan permainan bahasa dan gabungan antara media dan permainan ini mampu secara signifikan memberikan motivasi dan menarik minat siswa untuk ikut aktif terlibat dalam proses pembelajaran (Isnaini, Utami \& Marga, 2018). Penerapannya melibatkan seluruh siswa, baik siswa yang biasanya pasif maupun yang aktif. Dengan demikian, permainan ini sangat baik digunakan dalam kelas yang heterogen. Penerapannya melibatkan seluruh siswa, baik siswa yang biasanya pasif maupun aktif. Pembelajaran dilaksanakan dengan cara mempersiapkan kelengkapan seperti: sebuah kotak berukuran 30 × 20 x $15 \mathrm{~cm}$ dan di dalam kotak berisi kartu-kartu soal berbahan karton dengan ukuran $10 \times 15 \mathrm{~cm}$. Soal yang dibuat sesuai dengan materi. Kartu soal dapat berupa pertanyaan, gambar, dan jenis-jenis soal lainnya. Kotak dibuat semenarik mungkin dengan penuh warna, begitu pula dengan pembuatan amplop dan kartu soal. Agar siswa dalam mengerjakan soal tersebut menjadi tertarik dan ikut berpartisipasi sebaik mungkin dalam proses pembelajaran.Ukuran, jumlah amplop, dan kartu soal disesuaikan dengan materi pembelajaran yang akan disampaikan.

Proses pembelajaran fisika yang menarik akan membuat siswa lebih bersemangat dalam belajar. Dengan adanya penggunaan model dan media pembelajaran yang berbeda, menarik dan inovatif diharapkandapat meningkatkan minat siswa dalam belajar fisika. Sehingga, dengan tingginya semangat dan keinginan siswa untuk belajar dapat membuat hasil belajar menjadi lebih baik. Karena siswa jadi lebih aktif ketika di kelas dan dapat dengan sendirinya memahami konsep, prinsip dan teori dengan mengikuti kegiatan belajar yang diberikan oleh guru.

\section{METODE PENELITIAN}

Metode penelitian yang digunakan dalam penelitian ini adalah penelitian pengembangan (Research and Development) dengan model pengembangan Borg \& Gall. Penelitian ini bertujuan untuk mengembangakan KOMIKA sebagai media pembelajaran fisika pada materi impuls dan momentum. Prosedur penelitian pengembangan ini menggunakan model Borg \& Gall yang langkahnya terdiri dari (1) pengumpulan informasi, (2) perencanaan, (3) pengembangan bentuk awal produk, (4) uji lapangan awal, (5) revisi produk, (6) uji lapangan utama, (7) revisi produk operasional, (8) uji lapangan operasional, (9) revisi produk terakhir, dan (10) diseminasi dan implementasi. Teknik pengambilan data yang digunakan dalam penelitian ini dengan cara menguji coba produk yang dimaksudkan untuk mengumpulkan data yang dapat dipergunakan sebagai dasar untuk menetapkan tingkat efektifitas, efisien, dan atau daya tarik produk yang dihasilkan. Angket digunakan untuk menilai produk pengembangan oleh para ahli dan uji coba yang dilakukan di lapangan. Teknik analisis data yang dipergunakan untuk mengelola data dari hasil tinjauan ahli dan uji coba pengembangan yaitu menggunakan analisis statistik deskriptif dan analisis deskriptif kualitatif.

\section{HASIL DAN PEMBAHASAN}

Penelitian ini dilaksanakan dalam lima tahapan. Pada tahap pertama adalah pengumpulan informasi untuk menyusun konsep media pembelajaran pada mata pelajaran fisika yang akan dikembangkan. Informasi tersebut didapat melalui observasi di sekolah tentang keberlangsungan mata pelajaran fisika di dalam kelas, mengumpulkan informasi tentang media pembelajaran dan menentukan pokok bahasan yang akan dimasukkan dalam media pembelajaran. Dari hasil pengumpulan informasi tersebut diperoleh pokok bahasan Impuls dan Momentum, dan media pembelajaran KOKAMI (Kotak dan Kartu Misterius) berbasis Inquiry Learning yang akan dikembangkan. Pada tahap kedua adalah perencanaan yang meliputi menentukan tujuan pembuatan media pembelajaran KOKAMI (Kotak dan Kartu Misterius) berbasis Inquiry Learning. Pengembangan media pembelajaran ini bertujuan untuk membuat siswa menjadi lebih tertarik dalam pembelajaran fisika, menjadikan proses pembelajaran fisika lebih menyenangkan, serta menjadikan siswa lebih mandiri, aktif dan berfikir kritis. Selanjutnya, menentukan ahli untuk melakukan validasi serta menentukan sasaran yang akan menjadi subjek uji 
lapangan terbatas dan uji lapangan diperluas. Pada tahapan ketiga dalam penelitian ini adalah tersusunnya media pembelajaran KOKAMI (Kotak dan Kartu Misterius) berbasis Inquiry Learning yang berisikan materi fisika dengan pokok bahasan Impuls dan Momentum yang terdiri dari: kotak berukuran 30×30×20 cm, amplop soal yang terbuat dari kertas karton, dan kartu soal yang terdiri dari beberapa tipe soal yang diprint menggunakan kertas concord dengan beragam bentuk. Tahap keempat adalah uji lapangan terbatas yang dilakukan pada siswa kelas X Sekolah Menengah Atas. Pada tahap ini, peneliti mengambil sample secara acak untuk mendapatkan hasil validasi.Tahap kelima, melakukan revisi dari hasil uji lapangan terbatas. Tahap selanjutnya, peneliti melakukan uji lapangan diperluas.

Berdasarkan hasil validasi instrumen yang telah dilakukan dari aspek grafika, aspek penggunaan, aspek kebahasaan dan aspek ilustrasi didapat hasil seperti pada tabel 1 berikut ini.

Tabel 1. Hasil Validasi Instrumen

\begin{tabular}{|c|c|c|c|}
\hline No & Hasil Validasi Instrumen & Presentase & Kualifikasi \\
\hline 1 & Ahli & $89,44 \%$ & Baik \\
\hline 2 & Uji LapanganTerbatas & $78,81 \%$ & Baik \\
\hline 3 & Uji Lapangan Diperluas & $79,00 \%$ & Baik \\
\hline & Rata-rata & $82,42 \%$ & Baik \\
\hline
\end{tabular}

Berdasarkan tabel 1, dapat diketahui bahwa media pembelajaran KOKAMI (Kotak dan Kartu Misterius) berbasis Inquiry Learning dengan pokok bahasan impuls dan momentum yang dilakukan peneliti dapat termasuk dalam kualifikasi baik. Validasi yang telah dilakukan oleh para ahli, uji lapangan terbatas dan uji lapangan diperluas menghasilkan masukan-masukan yang kemudian ditindak lanjuti dengan dilaksanakannya revisi produk, adapun masukan-masukan yang didapat adalah sebagai berikut.

(1) Membuat kotak lebih menarik lagi seperti yang ditunjukkan pada gambar 1 dan gambar 2 dibawah ini.

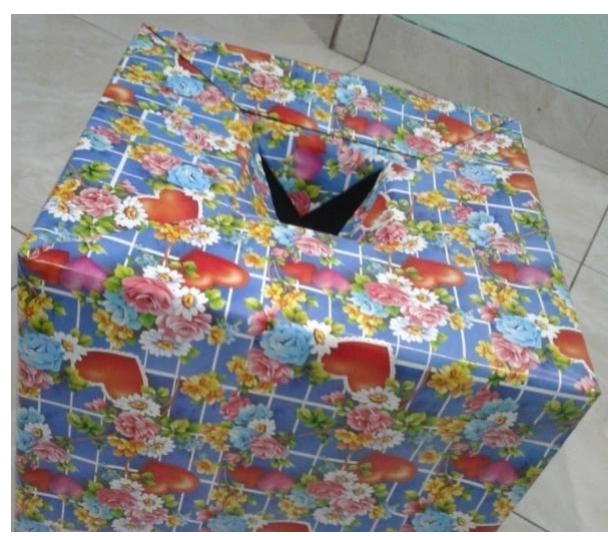

Gambar 1. Kotak sebelum diperbaiki

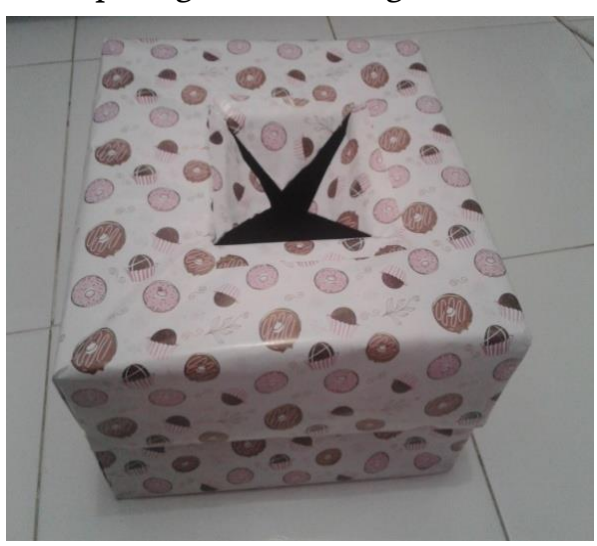

Gambar 2. Kotak setelah diperbaiki

(2) Memperbaiki soal uraian menjadi soal cerita ditunjukkan pada gambar 3 dan gambar 4 dibawah ini

Jawablah pertanyaan berikut dengan benar!

Bola golf bermassa $0,046 \mathrm{~kg}$ dipukul hingga melesat meninggalkan stik dengan kecepatan $60 \mathrm{~m} / \mathrm{s}$. Jika selang waktu kontak antara stik dan bola sebesar 0,05 sekon, tentukan gaya rata-rata yang dikerjakan stik!

Gambar 3. Kartu soal tipe uraian sebelum revisi 


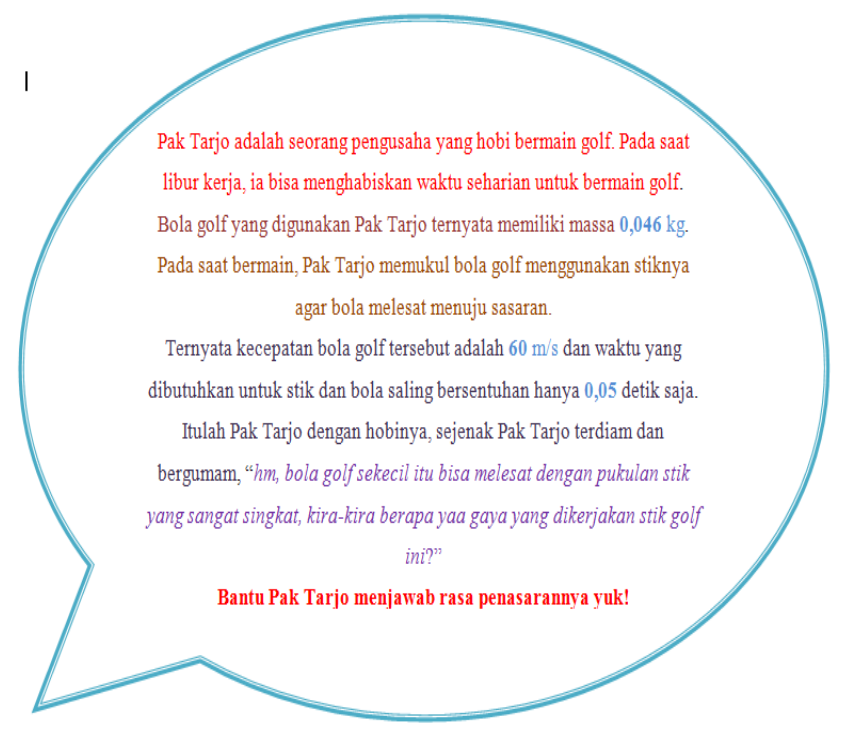

Gambar 4. Kartu soal tipe uraian setelah revisi

(3) Membuat amplop soal lebih menarik lagi ditunjukkan pada gambar 5 dan gambar 6 dibawah ini

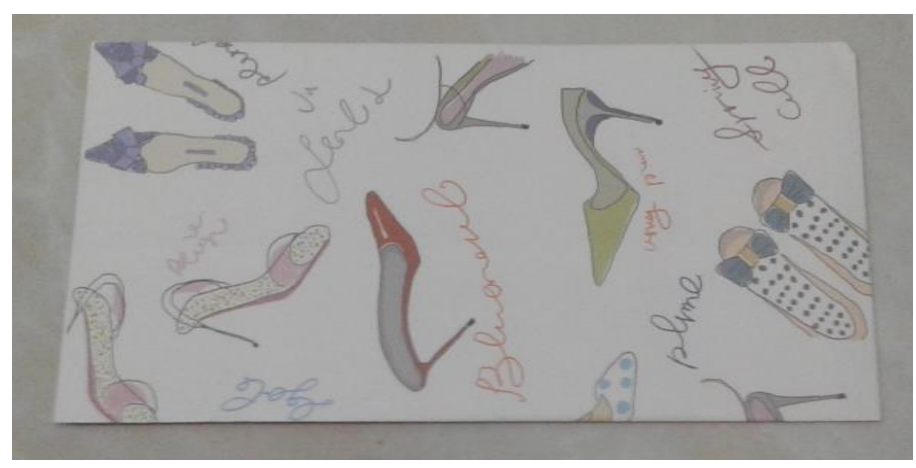

Gambar 5. Amplop soal sebelum revisi

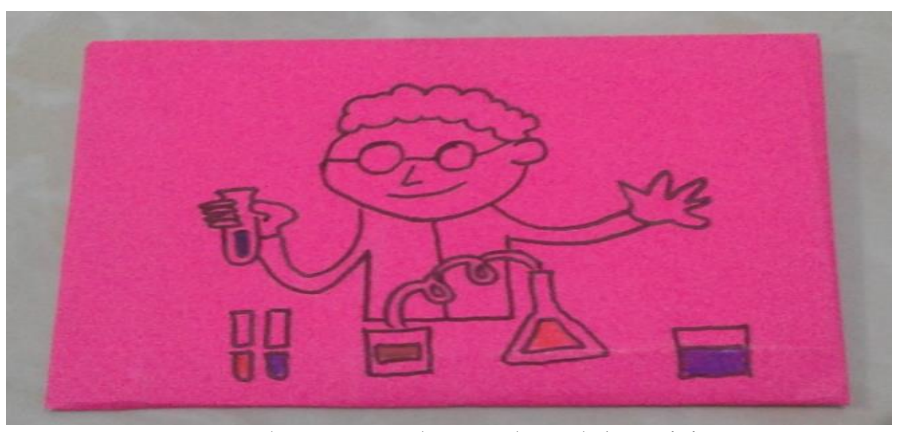

Gambar 6. Amplop soal setelah revisi

(5) Mengganti gambar dalam soal dengan buatan sendiri, (6) Menambahkan isi dalam kotak dengan aksesoris, (7) Membuat amplop soal lebih beragam, dan (8) Memperbesar ukuran tulisan agar lebih jelas.

Dari hasil uji validasi produk yang telah dilakukan dapat disimpulkan bahwa pengembangan media pembelajaran KOKAMI (Kotak dan kartu misterius) berbasis inquiry learning pada pembelajaran fisika menunjukan rata-rata niai yang masuk dalam kualifikasi Baik.

Dalam proses penelitian dibutuhkan juga adanya keefektivitas dalam penerapan media KOKAMI. Keefektivitas media pembelajaran dpat diketahui melalui hasil perhitungan dari nilai pretest dan posttest siswa pada saat sebelum dan sesudah adanya perlakuan ataupun penerapan media KOKAMI. Untuk mengetahui peningkatan hasil belajar siswa terhadap uji coba media pembelajaran KOKAMI maka peneliti menggunakan penilaian berupa soal pretest dan posttest 
kepada kelas yang akan digunakan uji penelitian. Soal pretest dilakukan sebelum adanya perlakuan atau permainan Kotak dan Kartu Misterius. Sedangkan untuk soal posttest dilakukan sesudah adanya perlakuan atau setelah melakukan permainan Kotak dan Kartu Misterius. Uji coba soal dilakukan pada satu kelas yakni dengan jumlah 30 siswa. Hasil yang diperoleh dari sebelum dan sesudah ujicoba penerapan media Kotak dan Kartu Misterius yang diujicobakan kepada 30 siswa. Bisa diketahui bahwa hasil dari pretest menunjukkan rata-rata 41,65 dengan kategori kurang tuntas dari uji coba 30 siswa. Sedangkan hasil dari posttest menunjukkan rata-rata 86,49 dengan kategori sangat tuntas dari uji coba 30 siswa. Dengan adanya hasil dari pretest posttest terdapat peningkatan hasil belajar yang tinggi karena sudah melakukan pembelajaran menggunakan media Kotak dan Kartu Misterius. Hal ini sesuai dengan penelitian Gammara \& Subroto (2019) yang menyatakan bahwa media pembelajaran KOKAMI dapat meningkatkan hasil belajar siswa.

Media pembelajarn KOKAMI selain meningkatkan hasil belajar siswa, tetapi juga meningkatkan keterampilan berpikir kritis (Rahmawati \& Kurniawan, 2017; Paisah, Fatmaryanti \& Akhdinirwanto, 2013; Isnaini, Utami \& Marga, 2018). KOKAMI (Kotak dan Kartu Misterius) dalam pembelajaran fisika merupakan salah satu media yang digunakan oleh guru untuk menarik perhatian siswa terhadap pelajaran fisika sehingga siswa termotivasi untuk mengikuti pembelajaran dan mencari tahu jawaban dari setiap pertanyaan atau pernyataan pada kartu pesan yang berada didalam amplop yang pula berada dalam kotak misterius. Penggunaan media pembelajaran kokami (Kotak dan Kartu Misterius) dalam pembelajaran fisika juga dapat membentuk keterampilan berpikir kritis siswa karena bersifat menantang dan dituntut berpikir kritis dalam menjawab pertanyaan dalam waktu terbatas sesuai dengan yang ditentukan juga siswa dapat meningkatkan tanggung jawab, kepercayaan diri, interaksi dan kerja sama dengan teman sekelompok,teman kelas dan guru. Penerapan media pembelajaran KOKAMI (Kotak dan Kartu Misterius) mempunyai dampak posistif dalam kegiatan pembelajaran, karena dapat menyebabkan proses penerimaan siswa terhadap pembelajaran akan lebih menyenangkan. Hal yang terpenting adalah perhatian siswa lebih berfokus pada pelajaran yang sedang berlangsung, sehingga membentuk pemahaman dan pengertian yang baik serta sempurna sesuai dengan tujuan penggunaan media kokami (Kotak dan Kartu Misterius) yang diharapkan.

Media belajar KOKAMI juga meningkatkan aktivitas belajar siswa. Hal ini senada dengan penelitian Rahmawati \& Kurniawan (2017) dan Nasution, Susilawati dan Haryati (2015) yang menyatakan bahwa aktivitas belajar siswa mengalami peningkatan saat menggunakan media KOKAMI, dengan adanya peningkatan aktivitas belajar membuat siswa terlibat aktif dalam proses pembelajaran. Dengan terlibatnya siswa secara aktif dalam pembelajaran juga akan meningkatkan motivasi siswa dalam belajar sehingga ketuntasan belajar akan tercapai. Secara garis besar, media pembelajaran KOKAMI yang dikembangkan layak dan dapat meningkatkan hasil belajar, kemampuan berpikir kritis, aktivitas belajar, dan motivasi siswa dalam belajar.

\section{PENUTUP}

Pengembangan media pembelajaran KOKAMI (Kotak dan Kartu Misterius) pada pelajaran fisika dinilai layak oleh ahli serta mendapatkan respon positif dari siswa. Media Pembelajaran KOKAMI selain meningkatkan hasil belajar, juga meningkatkan aktivitas belajar siswa, ketuntasan belajar, kemampuan berpikir kritis serta motivasi siswa dalam belajar. Media pembelajarn KOKAMI sangat layak diterapkan dalam proses pembelajaran di kelas.

\section{DAFTAR PUSTAKA}

Gammara, S. A., \& Subroto, W. T. (2019). Pengembangan Media Pembelajaran Kotak dan Kartu Misterius untuk Meningkatkan Hasil Belajar Siswa pada Mata Pelajaran Ekonomi Kelas X SMA. Jurnal Pendidikan Ekonomi, 12(2), 104-110.

Isnaini, M., Utami, L. S., \& Marga, K. M. (2018). Pengaruh media Kokami (kotak dan kartu misterius) terhadap keterampilan berpikir kritis dan motivasi belajar siswa kelas viii smp negeri 19 mataram 
tahun pelajaran 2017/2018. ORBITA: Jurnal Kajian, Inovasi dan Aplikasi Pendidikan Fisika, 4(2), 1825.

Istiqomah, F., Widiyatmoko, A., \& Wusqo, I. U. (2016). Pengaruh media kokami terhadap keterampilan berpikir kreatif dan aktivitas belajar tema bahan kimia. Unnes Science Education Journal, 5(2).

Mauliana, A., \& Rahmayani, R. F. I. (2017). Penerapan model pembelajaran kooperatif tipe teams games tournament (TGT) dengan menggunakan media kokami terhadap hasil belajar siswa pada materi perkembangan model atom kelas X MIA 4 SMA Negeri 9 Banda Aceh. Jurnal Ilmiah Mahasiswa Pendidikan Kimia, 2(3).

Nasution, W. N., Susilawati, S., \& Haryati, S. Penggunaan Media Pembelajaran Kotak dan Kartu Misterius (Kokami) untuk Meningkatkan Aktivitas dan Ketuntasan Belajar Siswa pada Pokok Bahasan Hidrokarbon dan Minyak Bumi di Kelas X. 8 Sman 9 Pekanbaru (Doctoral dissertation, Riau University).

Paisah, N., Fatmaryanti, S. D., \& Akhdinirwanto, R. W. (2013). Penerapan media kotak dan kartu misterius (Kokami) untuk peningkatan keterampilan berpikir kritis pada siswa kelas vii smp negeri 25 purworejo. Radiasi: Jurnal Berkala Pendidikan Fisika, 3(1), 28-32.

Putri, A. I. K. D., Prihandono, T., \& Putra, P. D. A. (2017). Penerapan model pembelajaran talking stick disertai metode demonstrasi berbantuan media Kokami mata pelajaran ipa di smp. Jurnal Pembelajaran Fisika, 5(4), 321-328.

Rahmawati, A. M. (2017). Analisis hasil pengembangan media kokami (kotak dan kartu misterius) untuk meningkatkan keterampilan berpikir kritis, aktivitas belajar dan ketuntasan belajar SMPSMA. Jurnal Pendidikan Ekonomi (JUPE), 5(3).

Rosarian, A. W., \& Dirgantoro, K. P. S. (2020). Upaya guru dalam membangun interaksi siswa melalui metode belajar sambil bermain [teacher's efforts in building student interaction using a game based learning method]. JOHME: Journal of Holistic Mathematics Education, 3(2), 146-163.

Rusiana, Y. (2014). Penggunaan Media KOKAMI pada Mata Pelajaran IPA untuk Meningkatkan Hasil Belajar Siswa Kelas VA SDN Darungan 01 Kecamatan Tanggul Kabupaten Jember. Pancaran Pendidikan, 3(4), 183-192. 